\title{
Manga yaoi y Fujoshis: exploración de la propia voz del deseo como alternativa al gobierno de la sexualidad juvenil ${ }^{1}$
}

Alexandra Chocontá Piraquive ${ }^{2}$

Investigadora Independiente, Bogotá, Colombia

alexandrachoconta@gmail.com

Recibido: 22 de septiembre de 2013

Aceptado: 10 de febrero de 2014

\footnotetext{
Artículo de reflexión derivado de la tesis de pregrado "Las Fujoshis y el Fanfiction yaoi: exploración de la "propia voz del deseo" femenino como alternativa al Gobierno de la Sexualidad Juvenil". Departamento de Antropologia, Pontificia Universidad Javeriana, Enero de 2013.

2 Antropóloga de la Pontificia Universidad Javeriana.
} 


\title{
Manga yaoi y Fujoshis: exploración de la propia voz del deseo como alternativa al gobierno de la sexualidad juvenil
}

\section{Resumen}

Este artículo presenta una reflexión sobre la apropiación en Colombia del manga yaoicómics japoneses que narran historias homoeróticas entre hombres- por parte de mujeres jóvenes aficionadas conocidas como fujoshis. Se propone que en este espacio de consumo las aficionadas desarrollan una propia voz del deseo femenino como alternativa al gobierno de la sexualidad juvenil, en el cual se implantan unas formas específicas de auto-vigilancia y autocontrol de la sexualidad juvenil femenina basados en un tipo ideal de deber ser mujer. Esta propia voz del deseo es reconstruida en el artículo a través de la contextualización del manga yaoi y su llegada al país, el acceso de las aficionadas al mismo y la manera en que ellas llegan a interpretarlo.

Palabras clave: sexualidad juvenil femenina; aficionadas; Yaoi; Fujoshis; Manga; Anime

\section{Yaoi Manga and Fujoshis: Exploration of the Own Voice of Desire as an Alternative to the Governance of Youth Sexuality}

\begin{abstract}
This article introduces a reflection on the adoption in Colombia of yaoi manga-Japanese comics that narrate homoerotic stories among men- by young fan girls known as fujoshis. It is suggested that in this space of consumption the fans develop their own voice of feminine desire, as an alternative to the governance of sexuality in youths. Said governance imposes specific ways of self-restrain and self-control of female sexuality in youths, based on an ideal type the way to be a woman. This own voice of desire is reconstructed in the article through the contextualization of yaoi manga and its arrival to the country, how fans have access to it, and how they get to interpret it.
\end{abstract}

Keywords: female youth sexuality, fans, yaoi, fujoshis, manga, anime

\section{Manga yaoi e Fujoshis: exploração da própria voz do desejo como alternativa ao governo da sexualidade juvenil}

\section{Resumo}

Este artigo apresenta reflexão sobre a apropriação na Colômbia do manga yaoi -quadrinhos japoneses que narram histórias homoeróticas entre homes- por parte de mulheres jovens aficionadas conhecidas como fujoshis. Propõe que neste espaço de consumo as aficionadas desenvolvem uma voz própria do desejo feminino como alternativa ao governo da sexualidade juvenil, na qual implantam-se formas específicas de autovigilância e autocontrole da sexualidade juvenil feminina baseadas em um tipo ideal de dever ser mulher. Esta voz própria do desejo é reconstruída no artigo através da contextualização do manga yaoi e seu arribo no país, o aceso das aficionadas ao mesmo e a maneira que elas conseguem interpretá-lo.

Palavras-chave: Sexualidade juvenil feminina; Aficionadas; Yaoi; Fujoshis; Manga; Anime 


\section{Introducción}

Como yaoi se conocen los cómics japoneses que narran historias homoeróticas entre hombres y son creados y consumidos principalmente por mujeres (Galbraith, 2011). El yaoi surgió a principios de 1970 en Japón como una actividad propia de las aficionadas al manga ${ }^{3}$ que parodiaban series famosas como Dragon Ball o Saint Seiya (Caballeros del zodiaco), dibujando a dos de sus personajes masculinos en una relación sexual (Kinsella, 1998) (Imagen 1). Estos dōjinshis (mangas creados por aficionados) empezaron a ser distribuidos e intercambiados, primero en círculos pequeños de aficionadas y posteriormente en convenciones más amplias de aficionados al manga, en donde el yaoi era ampliamente buscado y reconocido (Lunsing, 2006).

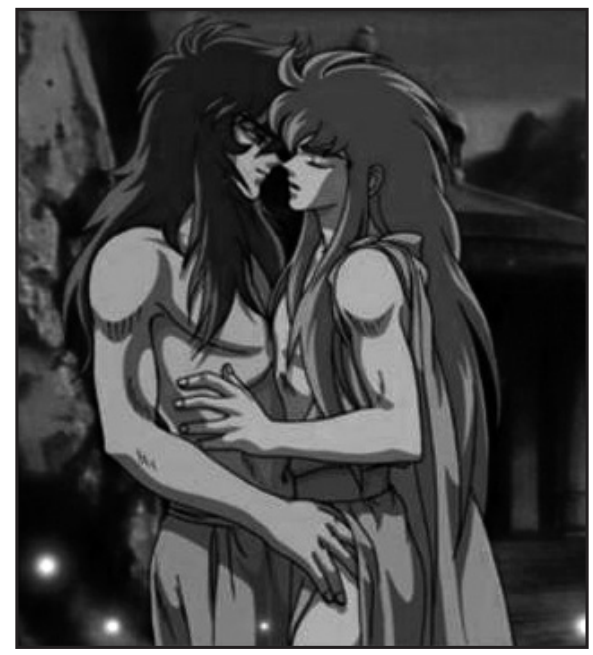

Imagen 1. Ejemplo de una parodia yaoi de la serie shonen Caballeros del zodiaco. Disponible en: http://www.saintseiyagallery.com/phpbb3/viewtopic. $\mathrm{php} \mathrm{f}=98_{\mathrm{ot}}=77938_{\mathrm{ov}} \mathrm{iew}=$ previous

La progresiva popularización que tuvo el yaoi, cuyo nombre es un acrónimo de la frase yama nashi, ochi nashi, imi nashi que en español significaría sin climax, sin desarrollo, sin significado (traducción mía) y hace referencia a las escenas sexuales que se representaban sin una argumentación concreta, permitió que algunas creadoras de yaoi pasaran

Manga es el término con que se conocen en Occidente los cómics producidos dentro de la industria editorial japonesa. Como anime se designan las versiones animadas de historias que previamente han sido publicadas en formato manga (Berndt, 1996). 
de parodiar series a publicar historietas originales en revistas de manga formales bajo el nombre de BL (Boys Love) ${ }^{4}$ (Saito, 2007). Varias de estas autoras no solo lograron publicar sus trabajos en revistas oficiales, sino también realizar secuelas y series animadas ganándose un lugar importante en la industria del manga, como sucedió con Minami Ozaki autora de la serie clásica de yaoi titulada Bronze (Imagen 2).

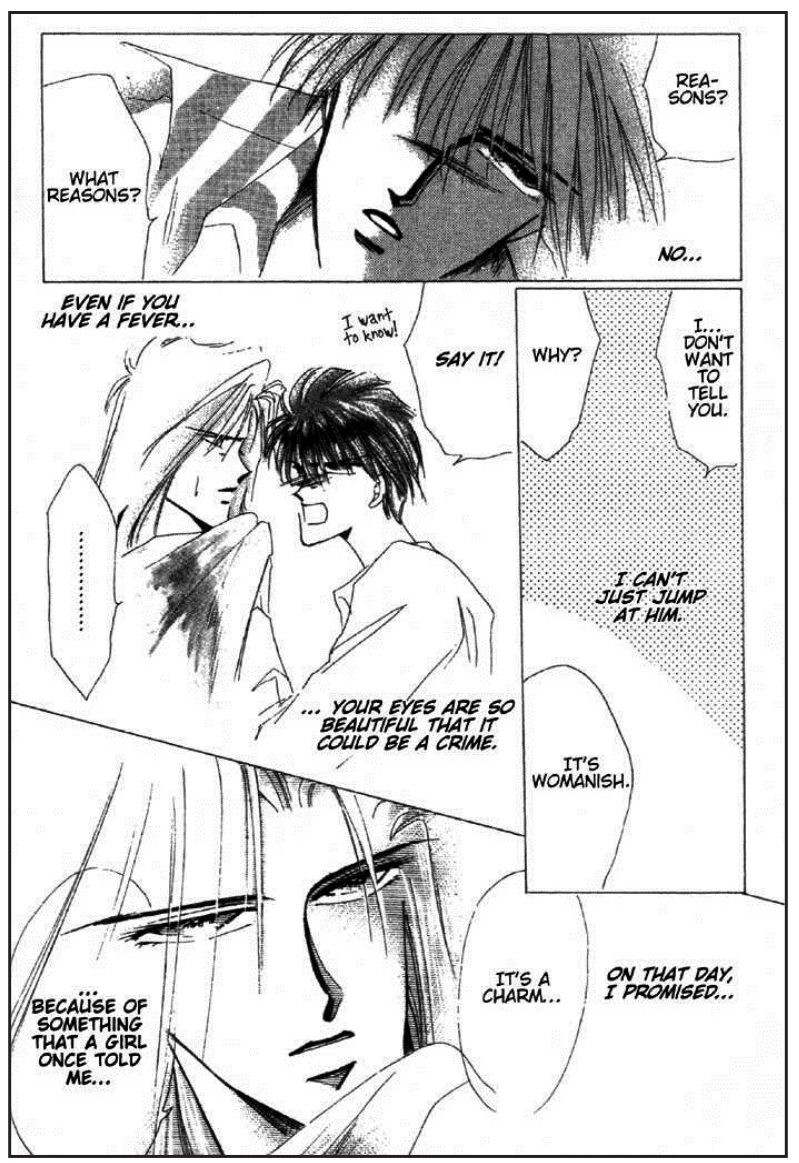

Imagen 2. Página del clásico manga yaoi Bronze, traducido por aficionadas al inglés. Allí aparecen los protagonistas teniendo uno de sus primeros encuentros emocionales en la serie. Disponible en: http://www.mangago.com/read-manga/bronze/mf/v01/c001/23/

4 En los circulos de aficionadas, las categorías Yaoi y BL muchas veces son equiparables y no poseen una naturaleza distinta. En este artículo utilizaré la categoría yaoi para referirme tanto a las parodias creadas por las aficionadas como a los títulos originales publicados. 
El yaoi como un sub-género oficial del manga y el anime dirigido a mujeres adultas en Japón se consolidó junto a otros sub-géneros más conocidos como el shonen ${ }^{5}$ y el shojo ${ }^{6}$, dándose a conocer en diferentes países de Suramérica (Díaz, 2009; Robles, 2011; López, 2012; Braga, 2013) y de habla inglesa (Levi, McHarry y Pagliassotti, 2010), entre otros ${ }^{7}$. Lejos de su lugar original de producción, el manga yaoi congregó en torno a sí a diferentes mujeres que también se denominaron como fujoshis": quienes "gustan de los chicos que gustan de otros chicos" (Braga, 2013) y se entusiasman con las historias y la estética a través de la cual son representados sus romances.

El consumo ${ }^{9}$ de estos mangas homoeróticos por parte de un público principalmente femenino tanto en Japón como en el extranjero, ha sido interpretado como un movimiento que re-construye patrones hetero-normativos para adaptarlos a los propios gustos e intereses de estas mujeres, quea través de los personajes masculinos representados en el yaoi, pueden imaginarse con personalidades más fuertes y libres y disfrutando de intensos y profundos encuentros sexuales (Kinsella, 1998; Saito, 2007) ${ }^{10}$.

En Colombia, la apropiación e interpretación del manga yaoi por parte de las aficionadas se encuentra mediado no solamente por una paradoja que pone en cuestión los estereotipos binarios y heterosexuales

5 El shonen es un sub-género del manga dirigido a hombres jóvenes que trata temas de amistad, aventuras y campeonatos (Braga, 2013). Series shonen conocidas son Dragon Ball Z, Caballeros del Zodiaco o Pokémon.

6 El shojo es un sub-genero del manga dirigido a mujeres jóvenes que trata temas sobre la amistad, la magia y el romance (Braga, 2013). Series shojo conocidas son Sailor Moon, Las Guerreras mágicas o Sakura Card Captors.

7 La distribución del yaoi por fuera de Japón, así como también de otros manga no comercializados en el extranjero, se debe en gran medida al trabajo de subtitulación y doblaje del japonés a otros idiomas por parte de los mismos aficionados que ayudan a popularizar a través de plataformas virtuales, series que aún no han sido, o que tal vez nunca serán dobladas y publicadas oficialmente en países por fuera de Japón (Ferrer, 2005).

8 Fujoshi es un término japonés que se traduce como mujeres decadentes o mujeres fallidas (traducción mía) y que apropiaron las aficionadas al yaoi para autodenominarse, pues su gusto por estas relaciones homoeróticas no se adecua al rol femenino japonés que deben ocupar y que relaciona estrechamente su sexualidad con la maternidad (Saito, 2007; Galbraith, 2011).

9 Al referirme al consumo de los aficionados hago alusión al término "consumo creativo" acuñado por Henry Jenkins (2008) según el cual los aficionados a los productos de la industria cultural apropian, modifican y distribuyen los contenidos que les atraen creando nuevas formas de producción cultural popular. Ejemplo claro de este "consumo creativo" es el yaoi, el cual nació de las parodias mismas que realizaban las aficionadas a manga shonen originales.

10 Esta forma de experimentación femenina a través de roles o personajes masculinos no es novedosa en el arte, pues como afirma Marcia Rejane (2011) en el teatro español del siglo XVII, los personajes femeninos constantemente eran disfrazados de hombres para lograr disfrutar prófugamente de un amor prohibido o para alejarse de las características femeninas tradicionales relacionadas con el amor, la seducción y el romance. Disponible en: http://marciarejane. wordpress.com/2011/05/02/la-mujer-vestida-de-hombre-en-el-teatro-espanol-del-siglo-xvii/ 
que le asignan a las mujeres un acercamiento desinteresado, pasivo y retraído a la sexualidad (Rubin, 1999; Hollibaugh, 1989), sino que también cuestiona de manera particular las pautas de buen comportamiento sexual que se les imponen en su juventud, pues en nuestro contexto el yaoi -un producto originalmente dirigido a un público femenino adultoes consumido mayoritariamente por mujeres en su adolescencia y juventud (McHarry, 2003; Napier, 2005; Cobos, 2009).

La juventud es para las mujeres una etapa en la que se presenta una forma particularmente represiva de la sexualidad ${ }^{11}$ pues aunque asta forma parte de la vida personal e intima, también empieza a ser configurada a través de regulaciones morales, económicas y religiosas que se implantan en sus cuerpos y restringen el grado de autonomía que pueden poseer sobre sí mismas ${ }^{12}$. Estas regulaciones dirigidas a las mujeres en su juventud se distribuyen en productos de la industria cultural como las revistas femeninas para adolescentes (Melo, 2006), así como también en los programas de salud sexual y reproductiva impartidos en las instituciones educativas (Viveros, 2004), en los que se las concibe como sujetos incapaces de tomar decisiones correctas sobre su sexualidad. Esto hace que se promuevan una serie de pautas (a manera de consejos) que hacen a las mujeres jóvenes centro de un proceso guiado de auto-regulación, planificación, cálculo y raciocinio de la sexualidad ${ }^{13}$ (Imagen 3).

11 Esta regulación empieza a promoverse con relativa fuerza a partir de la década de 1990 en las urbes colombianas donde la maternidad precoz se configura como un problema de orden demográfico, económico y de salud pública (Motta-Mejía, 2000).

12 Desde una concepciónmedicalizada, la sexualidad parte de un origen biológico que se empieza a desarrollar con fuerza en todos los individuos cuando llegan a la adolescencia y que en palabras de Checa (2005), se explica como "las transformaciones e impulsos de orden hormonal que obran sobre el cuerpo" y que son posibles de moldear a través de cambios en los estilos de vida y orientaciones pedagógicas especificas.

${ }^{13}$ Por ejemplo, en las revistas femeninas juveniles se combinan los conocimientos de anticoncepción básicos de los programas de salud sexual y reproductiva, junto a una serie de consejos que hacen un llamado a la sensatez, la reflexión, la autoestima y el respecto por sí mismas como bases de una sexualidad que debe convertir a las jóvenes en seres responsables y autónomos; protegiéndolas de esta manera de los peligros de la sexualidad masculina descrita como irracional e impulsiva (Melo, 2006). 


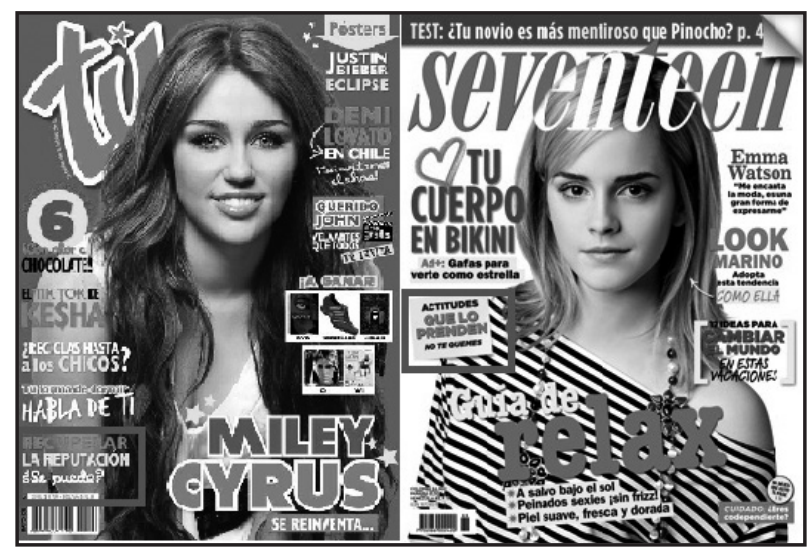

Imagen 3. Portadas de dos revistas femeninas juveniles que se distribuyen a nivel nacional. En ellas se puede leer los artículos que se tratan al interior de la revista como: "Recuperar la reputación ¿se puede?" o "Actitudes que lo prenden, no te quemes!" que enseñan y promueven un adecuado comportamiento sexual. Disponible en: http://pwp.etb.net.co/javier.antoni/portafolio/micrositios/televisa_colombia/ paginas/seventeen.html y http://tu.taconeras.net/tag/novedades-tu/

Propongo que a través del yaoi las aficionadas configuran un espacio en el que complejizan y ponen en cuestión algunas de las pautas de la sexualidad juvenil que se les inculcan, y en el que sus propias voces del deseo (Melo, 2006) permiten comprender formas alternas y autónomas de la sexualidad juvenil que no pasan por la auto-regulación, el control o el silencio. A través de la experiencia de una fujoshi bogotana de 19 años conocida como Misdaad ${ }^{14}$, se expondrá la manera en que se abren diferentes espacios de apropiación e interpretación del yaoi que permiten ampliar los marcos en los que entendemos la sexualidad juvenil femenina a la vez que se plantean las dificultades, contradicciones y conflictos que implica transgredirla.

$\mathrm{El}$ artículo se encuentra organizado de la siguiente manera: en primer lugar se presentarán algunas reflexiones metodológicas sobre los desafios de abordar a las aficionadas y sus exploraciones sobre la sexualidad como un objeto de estudio. Por un lado, se argumenta cómo la perspectiva del punto de vista u objetividad feminista (Haraway, 1995; Harding, 2004) permite encuadrar y contextualizar estas voces teniendo en cuenta su particularidad y su lugar marginal de enunciación. Por otro lado, se exponden los retos etnográficos que implica trasladarse y conectar las actividades virtuales de las fujoshis junto a sus actividades

\footnotetext{
${ }^{14}$ Nombre ficticio.
} 
de la vida real, como una única dimensión que repercute en la configuración de la sexualidad cotidiana.

En segundo lugar, se argumenta cómo las aficionadas al yaoi utilizan los medios virtuales para alejarse de las miradas adulto-centristas (Viveros, 2004) que regulan en los medios institucionales los conocimientos que como jóvenes se les permite saber y manejar sobre la sexualidad, desde una óptica que las concibe como sujetos incompletos urgidos de tutelaje.

Se explica entonces cómo las formas alternativas de circulación del yaoi y comunicación entre las fujoshis -desde la perspectiva de Misdaad- configuran un espacio que les facilita sostener relaciones de amistad y complicidad compartiendo a través del yaoi sus "propias voces del deseo" (Melo, 2006) al tiempo que implican contradicciones y conflictos con sus familiares y amigos. Igualmente se explican los motivos por los cuales Misdaad gusta del yaoi y cómo estos motivos se alejan en cierta medida de las convenciones pautadas para la sexualidad de las mujeres.

Por último, se esbozan algunas preguntas y perspectivas para futuros trabajos sobre el yaoi, las fujoshis y la sexualidad juvenil femenina.

\section{Precisiones y retos metodológicos}

Reconstruir la experiencia de Misdaad como aficionada al yaoi y comprender cómo se configura esta "propia voz del deseo" (Melo, 2006) implicó buscar lo que para ella misma encarnaba y significaba el yaoi y ser fujoshi, y cómo ello contradecía los principios del "gobierno de la sexualidad juvenil" (Viveros, 2004) que impone unos límites a los contenidos y conocimientos sobre la sexualidad que una mujer joven debe tener. Realizar esta contraposición de sentidos implica en un primer momento, darle validez y contexto a las voces que a partir del yaoi se producen sobre la sexualidad para las aficionadas.

Esta contraposición de conocimientos se desarrola a partir de lo que Donna Haraway (1995) describe como conocimientos privilegiados, entre los cuales se puede ubicar aquel que enuncia la sexualidad juvenil femenina desde una posición adulta y masculinista, pero que se presenta como una verdad objetiva, neutral y fiel a una ley universal biológica. Hablar entonces de los conocimientos alternos a estas verdades sobre la sexualidad implica privilegiar a las mujeres jóvenes 
aficionadas al yaoi como sujetos del conocimiento (Harding, 2004) que hablan desde su propia experiencia particular no-generalizable y desde la cual aportan a la creación de un conocimiento que habla de sí mismas, pero del que han estado social y politicamente excluidas.

Encarnar una posición de sujeto (Haraway, 1995) implica primero reconocer que todos los lugares de enunciación se configuran desde posiciones de opresión y privilegio paralelas y que en nuestro caso, se ubica en los cuerpos de mujeres jóvenes a quienes se les niega autonomía sobre su sexualidad, al tiempo que en el cuerpo de mujeres jóvenes privilegiadas que a través de su educación y de una alfabetización digital (Montenegro, 2010) significativa, logran acceder como aficionadas a los contenidos y comunidades del yaoi tanto virtuales como presenciales ${ }^{15}$.

Para rastrear la particularidad del lugar de enunciación de estas voces se recurrió a la experiencia de Misdaad, por ser ella una aficionada consolidada que participa en diferentes actividades relacionadas con el yaoi. A través de una serie de entrevistas etnográficas realizadas en el 2012, Misdaad me permitió recolectar información sobre cómo y qué había implicado acceder al yaoi, lo que significaba este subgénero para ella y cómo su afición la había llevado a crear relaciones de amistad con otras fujoshis e introducirse en otras de conflicto con sus familiares y amigos.

Esta experiencia para Misdaad estuvo atravesada fuertemente por una relación entre lo virtual y lo presencial, lo que hizo necesario abrir una reflexión sobre la necesidad de ubicar el espacio real y el virtual como dos escenarios que influyen paralelamente en la vida cotidiana de las personas, en tanto son vivenciadas como actividades que se llevan a cabo en contextos diferentes (contestar un email o comprar lo esencial en un supermercado) pero que hacen parte de una misma experiencia (Vázquez, 2011). En este sentido, la experiencia de Misdaad con el yaoi fue concebida de manera integral, en donde sus descubrimientos en el mundo virtual significaban la apertura de espacios y expresiones alternativas que influyeron en diferentes ámbitos de su realidad.

\footnotetext{
${ }^{15}$ La mayor convención de aficionados al manga y el cómic en general en Bogotá se conoce como SOFA (Salón del Ocio y la Fantasía) que en 2013 reunió aproximadamente a 80.000 visitantes en sus tres dias de presentación en las instalaciones de Corferias. (Ver: https://www.facebook. com/UniversoSOFA?fref $=$ ts).
} 


\section{Yaoi, fujoshis y censura en Colombia}

El adulto-centrismo que regula la sexualidad de las jóvenes y hace parte fundamental del "gobierno de la sexualidad juvenil" (Viveros, 2004) estuvo presente en la censura que sufrieron las series de anime (formato animado del manga) que llegaron al país ${ }^{16}$ y que fueron calificados como espantosos animados japoneses o muñecos diabólicos por parte de padres de familia e instituciones religiosas, que no estaban de acuerdo con que estas series fueran transmitidas a los más jóvenes por los canales nacionales de televisión (Cobos, 2009).

Para Tania Cobos (2010) esta polémica -que derivó en el progresivo retiro de las series de anime de la televisión nacional- surgió de lo que denominó como la "latinización del anime", un proceso de interpretación local de las series animadas japonesas, en el cual el desconocimiento de la popularidad del dibujo en la cultura nipona en Occidente hizo que series que estaban pensadas para públicos jóvenes y adultos fueran dirigidos a un público infantil en Latinoamérica ${ }^{17}$. Según Susan J. Napier (2005) esta interpretación es producto de la importancia que tiene la palabra escrita en Occidente en detrimento de la expresión gráfica y los dibujos, los cuales solo son aceptados en libros y productos dirigidos a niños y rara vez se piensan como un producto para adultos.

No obstante, a la par que esta controversia se iba desarrollando en el país, una voz de los consumidores tempranos del anime se expresó a través de la conformación de diferentes grupos, tanto virtuales como presenciales, de jóvenes que habían crecido con estas series y quienes buscando respaldo, comunicación y socialización, lograron difundir y profundizar su gusto y conocimiento por estas series animadas japonesas y el mundo de significados que encerraban.

Al ser Misdaad partícipe de estos cambios, también se trasladó -en su adolescencia- de las pantallas de televisión donde veía sus series shojo favoritas a internet, donde poseía una mayor libertad y

\footnotetext{
${ }^{16}$ La primera serie de anime transmitida en Colombia fue Heidi, la niña de los Alpes a través del canal Cadena 2 en 1976. Posteriormente se transmitieron algunas series dirigidas a niños como AstroBoy y Doraemon. Sin embargo, fue hasta la década de 1990 que un considerable número de famosos títulos de anime comenzaron a llegar a las pantallas nacionales como Sailor Moon, Super Campeones, Dragon Ball, Samurai X, Neon Genesis Evangelion, Pokémon, Digimon, Ranma 1/2, entre otros. (Ver: Series de animación japonesa en Colombia. Disponible en: http:/ /www.angelfire. com/anime5/rcotaku/anime_colombia.html)

17 Esta polémica también se presentó en Estados Unidos y en países europeos donde los dibujos animados japoneses eran equiparados a los dibujos de estudios como Disney y Warner Brothers dirigidos especialmente a un público infantil (Zuñiga, 2010).
} 
variedad para escoger las series que le llamaban la atención y donde accidentalmente encontró el yaoi.

Yo conocí el yaoi a los trece, pero realmente me vine a involucrar en este mundo a los catorce. Yo leía mucho manga shojo en ese entonces, yo era muy shojera en ese tiempo y resulta que llegué a un fansub [lugar en internet de traducción de manga] que se llamaba Menudo Fansub. Ahí había un manga que se llama Sakura Gari y que decía yaoi, yo pensé que era otro tipo de shojo, entonces lo descargué. Al comienzo fue como... no asimilaba bien la historia porque yo pensaba que obligatoriamente uno de los dos tenía que ser mujer, pero cuando vi que los dos eran hombres, entonces yo lo eliminé y mejor dicho pegué el grito en el cielo (risas). Después encontré un tomo que se llama Ladrón y Detective de Itsuki Kaname, era una relación muy leve pero se dieron un beso y yo dije: esta va a ser la única pareja de hombres que voy a aceptar. Después de eso, entre una y otra cosa pasaron como cuatro o cinco meses, después encontré Junjou Romantica (Imagen 4) de Shungiku Nakamura y ahí comencé a ver más series yaoi hasta estos dias (risas).

Internet se presentó entonces como una plataforma alejada de la regulación de la mirada adulta en la que podía tener mayor libertad para escoger por sí misma las series que quería ver. En este sentido, el yaoi representó una paradoja, pues aunque la primera serie yaoi que vio no le agradó precisamente por su contenido homoerótico, tampoco lo rechazó del todo pues siguió buscando y encontrando series yaoi que fue aceptando y que le fueron gustando a su propio ritmo.

En este sentido, la primera experiencia de Misdaad con el yaoi fue solitaria y respondió más a su propio interés y curiosidad para acercarse y comprenderlo. No obstante, a través de esta plataforma también logró contactar con otras aficionadas que ayudaron a ampliar su afición y gusto por el yaoi y con algunas de las cuales formaría más adelante el primer grupo de fujoshis bogotanas conocido como Emerald Romance (actualmente suBLime ciel):

Cuando yo me metí a un foro que se llamaba ForosDZ, entonces comencé [a conocerme] con otras chicas y me encontré con la primera amiga fujoshi que tuve [...]. La conocí a ella, pues empezamos a charlar y eso, cuando de un momento a otro ya en Facebook se empezó a abrir esa red y empecé a encontrarme con personas con las que podía contactar (personalmente) y me encontré con ella [...], 
me encontré con $[. .$.$] y pues hasta llegar al día de hoy que ya conozco$ a varias personas.

Para Misdaad ser fujoshi tiene diversos significados, por un lado una fujoshi no solo se diferencia de otras aficionadas a través del consumo de series yaoi, sino también en su producción a través de diferentes medios expresivos como dibujos (fanart) y escritos (fanfiction) yaoi que distribuyen por internet:

Obviamente yo creo que toda fujoshi ha tenido ese deseo, esas ganas de crear algo, que cuando no le sale a uno el dibujo uno uy gruñe, porque la idea sigue en la cabeza, entonces en ese caso cuando me di cuenta que podía expresar mis ideas con palabras, empecé a tropezar con los escritos y digamos que así fue la forma que yo comencé con los fanfiction, como un reto.

Por otro lado, para Misdaad las fujoshis son las aficionadas al yaoi que pese a las críticas que pueda suscitar su gusto particular por estas historias homoeróticas, se mantienen firmes en esta posición pues "es muy dificil encontrar a una chica fujoshi porque el prejuicio que existe es impresionante", en tanto puede ser visto como una degeneración por los mismos aficionados al manga en general ${ }^{18}$ y por los parientes y amigos cercanos:

Bueno pues yo vengo de una familia bastante conservadora, mi mamá es homofóbica, mi papá es homofóbico, mi hermano es homofóbico y por tanto, yo también lo era. Por eso el choque más duro fue con mi familia, yo duré dos años sin decirle a nadie [que veía yaoi], entonces digamos que el primer paso que di para decirle a mi mamá y a mi hermano [ella no le ha contado a su papá] fue que sí, que a mí me gustaba ver a dos hombres (...) hubo un rechazo rotundo de mi mamá, de hecho ese tema no se puede tocar, a pesar de que ella a veces lo toca inconscientemente y yo termino reaccionando, entonces ella empieza "estoy decepcionada de cómo puede gustarle eso". [...] Cuando yo les comenté [a sus amigos] así abiertamente "sí, que lo hagan dos hombres por mi está bien” ya comenzó el "¿a usted qué le pasa? ¡Qué porqueria!".

${ }^{18}$ Como evidencia Robles (2011), las fujoshis pueden ser concebidas en los mismos círculos de aficionados, como chicas feas y de baja autoestima que se obsesionan fácil e irracionalmente por el yaoi. 
Esta oposición con la que Misdaad tuvo que enfrentarse por su gusto por el yaoi con sus pares aficionados, sus amigos y familiares, permite entender cómo surge un rechazo tanto al yaoi como a ella por consumirlo; por salir de aquel lugar correcto de lo femenino que no se acerca a la sexualidad por iniciativa propia y menos a una relación no heterosexual. Por este motivo, el concepto de pornografia puede ser útil para comprender cómo la afición al yaoi permite una voz a las aficionadas en la cual cambian las posiciones básicas y tradicionales sobre a quiénes se les permite la excitación a través de la mirada.

Nosotras hacemos que los hombres pierdan todos sus valores, los pilares sobre los cuales el machismo se crea, porque ellos terminan reducidos a lo que nosotras esperamos de ellos, es decir, es una de las cosas que pienso cuando veo yaoi.

Para Beatriz Preciado (2008) la pornografia en Occidente se configuró como un privilegio exclusivo de una clase aristócrata, racional, adulta y masculina en el siglo XVI en Europa. Este control por género, edad y clase representó el momento fundacional del "control de la mirada, de vigilancia del cuerpo [masculino] excitado o excitable [...] por oposición a aquellos cuerpos [mujeres y niños] cuya mirada y placer debía ser protegido y controlado" (Preciado, 2008, pp. 45). En este sentido, Preciado comprende que la pornografia no son solo unas imágenes sexuales en sí, sino que se conforman en primera instancia por la regulación y el control del tipo de personas que pueden acceder a ellas sin ningún prejuicio moral.

La trasgresión de este límite es vital, pues a través del yaoi las aficionadas logran como mujeres jóvenes, acceder a contenidos que socialmente les son vetados y son exclusivos de un público que, en sentido figurado, pueden verlas a ellas pero no permiten ser vistos. En ese sentido, la pornografia también se configura por las cualidades de las imágenes sexuales que se muestran a un público exclusivo y que hablan de unas formas especificas (no únicas) de representar los cuerpos, la sexualidad y el placer (Preciado, 2008).

Para Misdaad el yaoi es "un género en el cual dos hombres tienen relaciones y muestran un tipo de relación sentimental que recurre al compromiso". Esta definición permite entender que para Misdaad los elementos del yaoi que más le llaman la atención no solo se centran en las imágenes sexuales que se muestran, sino en el contexto en el que se desarrollan: "ese mundo envuelto entre problemas, entre inseguridades, 
todo ese tipo de cosas me parecen perfectas, apasionantes [...] digamos las historias oscuras del yaol".

La relación romántica y sentimental que experimentan los personajes en el yaoi y que Misdaad describe como "un desarrollo bonito y natural entre dos hombres" es un elemento que, aunque se puede encontrar en otro tipo de dispositivos sociales como las revistas juveniles femeninas, se organiza de manera diferente en el yaoi, pues allí el romance no implica el aplazamiento de la sexualidad como un elemento final o postergado de la relación romántica, sino que se constituye como parte fundamental de la relación.

Anthony Giddens (2004), retomando el concepto de romance de la búsqueda de Sharon Thompson, identifica cómo el romance en la literatura Europea del siglo XVI tuvo una capacidad reflexiva y emancipadora a través de la construcción de un relato significativo con el otro, de la posible construcción de una biografía conjunta. No obstante, estas narrativas perdieron buena parte de su capacidad cuando se institucionalizaron, es decir, cuando se asociaron al matrimonio (monogamia) y a la entrega total de la mujer al esposo y los hijos.

En este sentido, se puede argumentar que en el yaoi esta institucionalización del romance no es tan clara y que los elementos del romance y la sexualidad no aparecen disociados sino que buscan conciliarse. A los ojos de Misdaad, que se declara como una "anti-fan de la romanticoneria", esta aparente conciliación es lo que logra que la relación se vea "bonita y natural".

Otro elemento que influencia el gusto de Misdaad por el yaoi se relaciona con la corporeidad de los personajes y la posición binaria femenino-masculino que ocupan. Un elemento constitutivo del yaoi es la consolidación de dos estructuras que definen la posición de los personajes que hacen pareja y que se conocen como el personaje seme (activo) que domina y guía la relación y el personaje uke (pasivo) que sigue la guía del seme en la relación (Saito, 2007). Estas dos posiciones se refieren tanto al acto sexual, donde el seme es penetrador y el uke es penetrado, como también a la asignación de roles en la que el seme representa lo masculino y el uke lo femenino (Kinsella, 1998) no solo en relación al comportamiento sino también a la apariencia física (Camper, 2006).

No obstante, para Misdaad esta división naturalizada de las relaciones de género y sexuales no representa un problema pues: 
[Los personajes] se diseñan así para idealizar las características que tenga su papel [por esto] cuando se está tratando de personificar a un seme, no se va a hacer chiquito, no se va a hacer tierno, ¿no? Entonces las características que se les asignan es para diferenciar entre el hombre que domina y el hombre que recibe y obviamente sabemos que las características del uke son muy parecidas a las de una mujer (Imagen4).

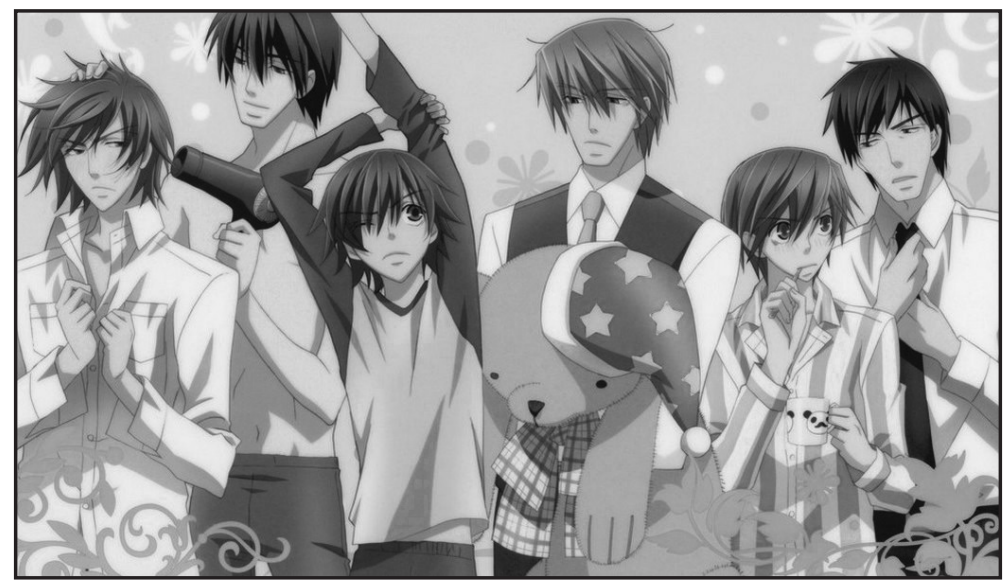

Imagen 4. Parejas principales de la serie de yaoi Junjou Romantica: pure romance de la autora Shungiku Nakamura. Esta serie publicada en 2002 y animada en 2008 es una de las series más populares y conocidas entre las aficionadas. Disponible en: http://anime.mx/sounds-junjou-romantica-ost/

Estas posiciones seme y uke en las que se organiza el yaoi son oposiciones desiguales construidas social y culturalmente basadas en la naturalización del sexo biológico (Rubin, 1999) que le asignan al hombre ser penetrador (activo) y a la mujer ser penetrada (pasiva), aunque en el yaoi está encarnación sea a través de dos cuerpos masculinos. Estas características sin embargo, no son únicas del yaoi pues las relaciones homosexuales entre hombres también se viven desde los roles de género dominantes, en las que uno de los hombres conserva sus condiciones masculinas al ser dominante y denominado popularmente como cacorro y el otro, que retoma actitudes afeminadas y pasivas y se denomina popularmente como marica (Serrano, 1997). Estas dos connotaciones cacorro y marica son equiparables a las de seme y uke y evidencian la fortaleza de la socialización binaria de género en la cual pareciese que las únicas relaciones sexuales posibles e imaginables están basadas en la dicotomía activo/pasivo, dominante/sumiso. 
Las características anteriormente mencionadas del yaoi, tanto las implicaciones mismas en su acceso como los contenidos que transmiten, nos permiten comprender algunas posibles fugas de escape y reproducciones del sistema dominante de la sexualidad femenina presente en esta propia voz del deseo. A los ojos de Misdaad, algunas de estas características pasan desapercibidas o en otras palabras, no son parte de una reflexión profunda respecto a los estereotipos que pueden llegar a reproducir, pues en el romance la sexualidad, el drama y las características de los personajes residen en los motivos de su aceptación.

Existe una contradicción fundamentalen este espacio de la sexualidad juvenil femenina que se configura alrededor del yaoi y para las aficionadas que se identifican como fujoshis. Alli se reproducen y reedifican los roles binarios y desiguales de género en las posiciones seme/uke, al tiempo que en el acceso mismo a estas series, ellas revocan el estereotipo sexual que se les impone, en el cual tienen que mantener una sexualidad ingenua, un rechazo a cualquier material obsceno por ser estos los lugares correctos de su deber ser como mujeres jóvenes, siempre vistas pero nunca en la capacidad de ver o decidir.

\section{Conclusiones y perspectivas para futuros trabajos}

A lo largo de este artículo se presentó la perspectiva de una aficionada al yaoi y cómo lograba contestar ciertos estereotipos de la sexualidad juvenil femenina. La configuración de esta propia voz nos llevó por diferentes momentos de apropiación que pasaron por la censura del anime en los canales de televisión nacional, hasta la consolidación de grupos de aficionados que recibieron positivamente estas y otras series a través del manejo de diferentes plataformas virtuales de comunicación.

Esta recepción ayudó a conformar un espacio de autonomía juvenil que da cuenta de la formación que en los últimos años ha tenido en el país la creación de nuevos espacios de participación politica de los jóvenes que no corresponden a los espacios tradicionales sino a uno en el que los jóvenes, en sus intereses particulares, sus gustos y pasiones, crean nuevas subjetividades y formas de expresión como resulta ser en el caso de las fujoshis.

La propia voz del deseo que alli se expresa y que buscamos contextualizar y explorar en este artículo no obstante, debe seguir siendo estudiada en otras facetas como en la múltiples actividades de creación que 
tienen las fujoshis en las que dibujan sus propios manga yaoi, escriben sus historias yaoi u organizan concursos y reuniones de fujoshis para compartir este material y socializar entre sí. En estos otros espacios pueden existir características importantes que siguen dándole forma a esta voz y a través de los cuales ellas pueden estar refutando algunos de los contenidos que reproducen los estereotipos de género en el yaoi, o bien crear nuevas formas de interpretación o esquemas para esos mismos contenidos.

\section{Referencias}

Berndt, J. (1996/1995). "Sueños de amor" y “fantasías adultas". En El fenómeno manga (pp. 93-153). Barcelona: Ediciones Martínez Roca, S.A.

Braga, X. (2013). A diversidade homoafetiva nos quadrinhos japoneses: educação sexual, pornografia ou mercado erótico? Latitude, 07 (1). Disponible en:http://www.seer.ufal.br/index.php/latitude/article/view/1066

Camper, C. (2006). "Yaoi" 101: Girls love "Boys' love". The women's review of books. 23(3), 24-26.

Checa, S. (2005). Implicancias del género en la construcción de la sexualidad adolescente.Anales de la educación común, 1, 1-8. Disponible en: http:// areasgyr.files.wordpress.com/2011/03/genero-identidad-adoles.pdfCobos, T. (2009). La animación japonesa desde el contexto occidental. Disponible en: http: / tanialu.co/2009/05/26/la-animacion-japonesa-desde-el-contextooccidental/

Cobos, T.. (2010, mayo-julio). Animación japonesa y globalización: la latinización y la subcultura otaku en América Latina. Razón y palabra. 1(72). Disponible en: http://www.razonypalabra.org.mx/N/N72/Varia_72/32_Cobos_72.pdf

Díaz, J. (2009). Formas emergentes de la literatura: el fanfiction desde los estudios literarios. Tesis de pregrado no publicada. Pontificia Universidad Javeriana. Bogotá.

Ferrer, M. R. (2005). Fansub y scanlations: la influencia del aficionado en los criterios profesionales.Puentes, (6), 27-44.Disponible en:http://www.ugr. es / greti/puentes/puentes6/04\%20Maria\%20Rosario\%20Ferrer.pdf

Galbraith, P. (2011). Fujoshi: fantasy play and transgressive intimacy among "rotten girls" in Contemporary Japan. Signs, 37 (1). Disponible en: http: / www. jstor.org/stable/10.1086/660182

Giddens, A. (2004/1992). "Amor romántico y otras formas de afectividad" y "Amor, compromiso y el nuevo modelo de relación afectiva". En La transformación de la intimidad. Sexualidad, amor y erotismo en las sociedades modernas (pp. 43-52; 53-65). Madrid: Ediciones Cátedra. 
Haraway, D. (1995/1991). Conocimientos situados: la cuestión científica en el feminismo y el privilegio de la perspectiva parcial.Ciencia, cyborgs y mujeres. La reinvención de la naturaleza (pp 313-346.). Cátedra: Madrid.

Harding, S. (2005). Introduction: standpoint theory as a site of political, philosophic, and scientific debate. En The feminist standpoint theory reader, intellectual and political controversies (pp. 1-13). New York:Routledge.

Hollibaugh, A. (1989). El deseo del futuro: la esperanza radical en la pasión y el placer. En Placer y peligro. Explorando la sexualidad femenina (pp. 191-204). Madrid: Talasa ediciones.

Jenkins, H. (2008). Introducción: "adoración en el altar de la convergencia: un nuevo paradigma para comprender el cambio mediático", "¿La guerra de las galaxias de Quentin Tarantino? La creatividad popular se enfrenta con la industria mediática" y "Por qué sabe escribir Heather: La alfabetización mediática y las guerras de Harry Potter". En Convergence culture, la cultura de la convergencia de los medios de comunicación(pp. 13-34; 137-173; 175-208). Barcelona: Paidós.

Kinsella, S. (1998). Japanese subculture in the 1990s: Otaku and the amateur manga movement. Journal of Japaneses studies, 24 (2), 289-316.

Levi, A., McHarry, M. y Pagliassotti, D. (Eds.) (2010). Introduction. En Boys' Love Manga: Essays on the Sexual Ambiguity and Cross-cultural Fandom (pp. 1-8). Jefferson, NC: McFarland.

López, C. (2012). Problemas de genre/gender en objetos de la cultura masiva: el género yaoi - shounen ai desde una perspectiva interdisciplinar. En Actas del segundo congreso interdisciplinario sobre Género y Sociedad: "lo personal es politico" (pp. 1-8). Argentina: Universidad Nacional de Córdoba. Disponible en: http:/ / publicaciones.ffyh.unc.edu.ar/index.php/2congresogeneroysociedad/ article/view/871

Lunsing, W. (2006). Yaoi Ronso: Discussing depictions of male homosexuality in Japanese girls' comics, gay comics and gay pornography. Intersections: Gender, history and culture in the asian context, 12 (Queer Japan). Disponible en:http://intersections.anu.edu.au/issue12_contents.html

McHarry, M. (2003). Yaoi: Redrawing Male Love. The Guide, 23, 29-34. Disponible en: http://classic-web.archive.org/web/20080417001927/http:// www.guidemag.com/temp/yaoi/a/mcharry_yaoi.html.

Melo, M. (2006). Representaciones de la sexualidad en las revistas femeninas juveniles. En Viveros, M. (Ed.). Saberes, culturas y derechos sexuales en Colombia(pp. 215-230). Bogotá: Tercer Mundo Editores del Grupo TM s.a. Centro Latinoamericano de Sexualidad y Derechos humanos ClAM, Centro de Estudios Sociales Ces.

Montenegro, J. (2010). Nuevas tecnologías y agenciamiento juvenil: aproximación desde el ciberfeminismo. Revista de estudios de juventud, (89), 221-234. 
Motta-Mejía, I. (2000). Presentación, Introducción y Conceptualización básica. En Dinámicas, ritmos y significados de la sexualidad juvenil (pp. 15-16). Bogotá: Programa La Casa; CESO Universidad de los Andes.

Napier, S. (2005). The problem of existence in Japanese animation. Proceedings of the American philosophical society, 149 (1), 72-79.

Preciado, B. (2008). Museo, basura urbana y pornografia. Zehar: revista de Arteleku-ko aldizkaria, (64), 38-67.

Robles, N. (2011).Sexualidad 2D: política, imaginación y libido dentro de una subcultura posmoderna. Razón y palabra, (77). Disponible en:http://www. razonypalabra.org.mx/N/N77-2/08_Robles_M77-2.pdf

Rubin, G. (1999/1975). El tráfico de mujeres: Notas sobre la "economía política" del sexo. En Lamas, M. (Comp.) El género: la construcción cultural de la diferencia sexual (pp. 35-96). México: UNAM - PUEG - Miguel Ángel Porrua..

Saito, T.(2007).Otaku sexuality. En Bolton, C.et al (Eds,). Robot ghost and wired dreams: Japanese science fiction from origins to anime(pp. 222-247). Minessota: University of Minnesota Press.

Serrano, J. F. (1997). Entre negación y reconocimiento. Estudios sobre "homosexualidad" en Colombia. Nómadas, (6).Disponible en: http://www. redalyc.org/src/inicio/ArtPdfRed.jsp?iCve=105118999006

Vance, C. (Comp.) (1989). El placer y el peligro: hacia una politica de la sexualidad. En Placer y peligro. Explorando la sexualidad femenina (pp. 9-49). Madrid: Talasa ediciones.

Vázquez, J. (2011). Lo "real" y lo "virtual": una reflexión sobre la implicancia del uso de estos conceptos en el análisis antropológico sobre las interacciones en la Red.ETNICEX, (3), 27-44.

Viveros, M. (2004, enero-diciembre). El Gobierno de la Sexualidad Juvenil y la gestión de las diferencias. Reflexiones a partir de un estudio de caso colombiano. Revista Colombiana de Antropología, 40, 155-184.

Zuñiga, D. (2010). La estructura narrativa del anime. Caso de la serie Naruto. Tesis de maestría no publicada. Pontificia Universidad Javeriana. Facultad de comunicación y lenguaje.

\section{Cómo citar este artícuo}

Chocontá, A. (2015). Manga yaoi y fujoshis: exploración de la propia voz del deseo como alternativa al gobierno de la sexualidad juvenil. Universitas Humanistica, 79, 211-229. http://dx.doi.org/1011144/Javeriana.UH79.myfp 